\title{
The Phase Space as a New Representation of the Dynamical Behaviour of Temperature and Enthalpy in a Reefer monitored with a Multidistributed Sensors Network
}

\author{
T. Jiménez-Ariza • E. C. Correa • B. Diezma • A. C. Silveira • P. Zócalo • F. J. Arranz • \\ A. Moya-González • M. Garrido-Izard • P. Barreiro • M. Ruiz-Altisent
}

Received: 9 May 2013 / Accepted: 2 September 2013

(C) Springer Science+Business Media New York 2013

\begin{abstract}
The study of temperature gradients in cold stores and containers is a critical issue in the food industry for the quality assurance of products during transport, as well as for minimizing losses. The objective of this work is to develop a new methodology of data analysis based on phase space graphs of temperature and enthalpy, collected by means of multidistributed, low cost and autonomous wireless sensors and loggers. A transoceanic refrigerated transport of lemons in a reefer container ship from Montevideo (Uruguay) to Cartagena (Spain) was monitored with a network of 39 semi-passive TurboTag RFID loggers and 13 i-button loggers. Transport included intermodal transit from transoceanic to short shipping vessels and a truck trip. Data analysis is carried out using qualitative phase diagrams computed on the basis of Takens-Ruelle reconstruction of attractors. Fruit stress is quantified in terms of the phase diagram area
\end{abstract}

T. Jiménez-Ariza • E. C. Correa • B. Diezma • A. Moya-González • M. Garrido-Izard $\cdot$ P. Barreiro $\cdot$ M. Ruiz-Altisent

Laboratorio de Propiedades Físicas y Tecnologías Avanzadas en Agroalimentación, Departamento de Ingeniería Rural, ETSI

Agrónomos, Universidad Politécnica de Madrid-CEI Moncloa, Av.

Complutense s/n, Ciudad Universitaria, 28040 Madrid, Spain

E. C. Correa $(\square)$

Departamento de Ciencia y Tecnologías Aplicadas a la Ingeniería Técnica Agrícola, EUIT Agrícola, Universidad Politécnica de Madrid-CEI Moncloa, Av. Complutense s/n, Ciudad Universitaria, 28040 Madrid, Spain

e-mail: evacristina.correa@upm.es

A. C. Silveira $\cdot$ P. Zócalo

Poscosecha de Frutas y Hortalizas, Facultad de Agronomía, Universidad de la República, Avda. Garzón 780, 12300 Montevideo, Uruguay

\section{F. J. Arranz}

Grupo de Sistemas Complejos, ETSI Agrónomos, Universidad Politécnica de Madrid-CEI Moncloa, Av. Complutense s/n, Ciudad Universitaria, 28040 Madrid, Spain which characterizes the cyclic behaviour of temperature. Areas within the enthalpy phase diagram computed for the short sea shipping transport were 5 times higher than those computed for the long sea shipping, with coefficients of variation above $100 \%$ for both periods. This new methodology for data analysis highlights the significant heterogeneity of thermohygrometric conditions at different locations in the container.

Keywords Perishable products · Fruit transport $\cdot$ Logistics · Phase space reconstruction $\cdot$ Psychrometry $\cdot$ RFID

\section{Introduction}

Food industry is in a permanent quest for new markets and new population sectors, which immediately translates into the search for novel products and more efficient processes to gain market opportunities (Juriaanse 1999; Bruin and Jongen 2010). In a scenario where global trade of perishable goods grew $7.6 \%$ in the first 6 months of 2011, the high losses incurred in the postharvest processes due to a decrease in the quality and/or shortening of the shelf life of fruits and vegetables, justifies the need to invest in better postharvest handling. On the other hand there is a need for proper management of the supply chain to ensure the availability of a high quality, safe and traceable product, in the right time and place in markets where it is consumed at minimum cost (Yahla 2009).

The starting point for this study is the quality of fruits and vegetables: it is well known that it changes rapidly when inadequate temperature and relative humidity $(\mathrm{RH})$ conditions occur during transport and storage. Several studies have shown a significant level of temperature and humidity heterogeneity, with non-uniform airflow in the refrigeration equipment, which lead to a deterioration in food quality and safety. Inadequate temperatures are the second factor causing food-borne illness, 
being the first the initial microflora present in the commodity foods (Laguerre et al. 2013; Pathare et al. 2012; RodriguezBermejo et al. 2007). Transportation and logistics have a significant role in the process, so that there is the need for supervision, control and modeling to evaluate/simulate and estimate the quality state with which the loads reach their destination. Transportation is an important part of the overall quality system and must provide a complete logistics service, based on scientific and technological aspects and on information management (Costa et al. 2013).

Rapid advances in sensors and wireless communications have the potential to assist in dealing with a large amount of data generated by a monitoring system. Low-cost, wireless and autonomous sensors, from the point of view of power supply and recording capabilities, are the most suitable for the supervision and control of cold chambers such as a reefer container (Costa et al. 2013). These allow us to install intensive and real-time data acquisition networks that make the reconstruction of the time and spatial distribution of variables such as temperature or fluid velocity fields feasible from point measurements (Garcia et al. 2007). Models can be developed to explain and to predict temperature changes, as for example in a corner or the center of a banana box inside a pallet in a reefer container to be used as a helpful tool to predict the emergence of warm spots (Jedermann et al. 2013). Other models of the environment in refrigerated transport units are addressed to the prediction of heat and mass transfer during transportation and can combine variables as temperature again, with time aspects of transportation, such as fluctuating external ambient conditions, door openings, product removal/loading (James et al. 2006). The "intelligent container" developed by Lang et al. (2011) is equipped with 16 sensor nodes each containing a temperature and humidity sensor. The system uses several algorithms in order to estimate temperature related quality losses, to detect malfunctioning sensors and to control the sensor density to provide an accurate spatial interpolation and measurement intervals.

Therefore, temperature is a well-established indicator for monitoring the transport conditions of fresh products. However, little information about humidity is usually registered and used. Enthalpy is actually a measure of the total energy held in the air by two components: sensible energy, measured by dry bulb temperature, and latent energy, which is the heat retained in water vapor allowing it to remain as such. It should be underlined that enthalpy values could be a more accurate predictor of stress, because they provide humidity variation as well (Villarroel et al. 2011). Furthermore, in previous studies a correlation was found between energy consumption and enthalpy (García Hierro et al. 2010). Air enthalpy dynamics evolves continuously due to temperature and humidity variations inside a cold chamber and the resultant enthalpy peaks usually correspond to increases in energy consumption (Barreiro et al. 2010). In other fields of knowledge, control systems based on enthalpy instead of temperature are preferred (Aktacir et al. 2008; Bulut and Aktacir 2011). Previous research demonstrated the convenience of enthalpy control strategy against temperature control strategy for free cooling applications (Aktacir 2012).

On the other hand, the phase space (or phase diagram) is the most adequate representation where the behavior of a dynamical system is displayed. In principle, we should know the corresponding differential equation system, solve it for a given initial conditions, and then plot the solution in the phase space representation. However, as proven by Packard et al. (1980), Takens (1981), Eckmann and Ruelle (1985), and other authors, a topological approximation to the phase space of a dynamical system can be obtained from a time series corresponding to one of its solutions. That is, we can approximately reconstruct the phase space of an unknown dynamical system through a time series obtained by measuring one of its physical variables along time. In this paper, we apply this reconstruction technique to temperature and enthalpy data, in order to analyze the two-dimensional projections of the derived phase space.

The objective of this work is to develop a new methodology of data analysis based on the implementation of phase space graphs of temperature and enthalpy. Data are collected by multidistributed, low-cost and autonomous wireless sensors and loggers, while phase space charts are used as a quick tool for the characterization of the spatial gradients of temperature, $\mathrm{RH}$ and enthalpy in a refrigerated room.

\section{Materials and Methods}

\section{Experimental Setup}

A transoceanic ship of a $40^{\prime}$ High Cube reefer $(11.59 \times 2.3 \times$ $2.43 \mathrm{~m}$ for internal dimensions), loaded with $25,000 \mathrm{~kg}$ of lemons was monitored: origin from Montevideo (Uruguay) and destination to Cartagena (Spain). The container was fully loaded with 20 pallets. Telescopic boxes $(15 \mathrm{~kg})$ of corrugated carton and with overall external dimensions $395 \times 295 \times$ $275 \mathrm{~mm}$ (length $\times$ width $\times$ height) were palletized in eight layers with ten boxes per layer. The area of openings represented $10 \%$ of the overall external surface of each box, with circular openings, four at the top and four at the bottom, and 12 rectangular openings in the sides of the boxes. Table 1 shows the complete itinerary followed by the reefer during 31.7 days. The first 22.2 days of travel were made in the Maersk Laberinto vessel from port of Montevideo to port of Algeciras (Spain), then the container was transferred to a second vessel, the BF Maryam, this stage of the journey lasted 9.5 days. Finally, the reefer was transported by truck $(2 \mathrm{~h})$ from the port of Cartagena to the fruit packinghouse in Murcia (Spain).

The multidistributed sensor network was made up by 45 TurboTag (RFID Tags) temperature sensors (only 39 correctly collected the data), and 15 i-button temperature and $\mathrm{RH}$ 
Table 1 Lemons' itinerary with indication of sea distances (in nautical miles) and vessel speeds (in knots)

\begin{tabular}{|c|c|c|c|c|c|c|c|c|}
\hline \multirow[t]{2}{*}{ Vessel } & \multirow[t]{2}{*}{ Port } & \multirow[t]{2}{*}{ Time zone } & \multirow{2}{*}{$\begin{array}{l}\text { Distance } \\
\text { (nautical miles) }\end{array}$} & \multirow{2}{*}{$\begin{array}{l}\text { Speed } \\
\text { (knots) }\end{array}$} & \multicolumn{2}{|l|}{ Days } & \multirow[t]{2}{*}{ Arrival } & \multirow[t]{2}{*}{ Departure } \\
\hline & & & & & At the sea & In poit & & \\
\hline \multirow[t]{4}{*}{ Maersk Laberinto } & Montevideo (Uruguay) to & GMT -3.0 & 789 & 7 & 5.6 & 2 & $28 / 07 / 12$ & $30 / 07 / 12$ \\
\hline & Sao Francisco do Sul (Brazil) to & GMT -3.0 & 155 & 10 & 1.6 & 1 & $04 / 08 / 12$ & $05 / 08 / 12$ \\
\hline & Santos (Brazil) to & GMT -3.0 & 4381 & 17 & 10.7 & 1.3 & $06 / 08 / 12$ & $07 / 08 / 12$ \\
\hline & Algeciras (Spain) to & $\mathrm{GMT}+1.0$ & 17 & 7 & 0.1 & 4 & $17 / 08 / 12$ & $21 / 08 / 12$ \\
\hline \multirow[t]{3}{*}{ BF Maryam } & Ceuta (Spain) to & $\mathrm{GMT}+1.0$ & 234 & 8 & 1.2 & 0.2 & $22 / 08 / 12$ & $22 / 08 / 12$ \\
\hline & Cartagena (Spain) & $\mathrm{GMT}+1.0$ & & & & 4 & $23 / 08 / 12$ & $27 / 08 / 12$ \\
\hline & TOTAL & & 5,576 & & $19.2(60.3 \%)$ & $12.5(39.7 \%)$ & & \\
\hline
\end{tabular}

sensors (only 13 of them correctly collected the data). The sensors were equi-spatially distributed along the load of approximately $62 \mathrm{~m}^{3}$, and were attached to the inner surface of the cartons. Five transversal planes (parallel to the door) were defined (Table 2). For TurboTag, nine sensors were equi- spatially located on each transversal plane (three per height); and for i-buttons, only one sensor per height was located in each transversal plane. Table 2 shows the technical characteristics of both types of sensors, both low cost (between $25 \$$ for TurboTag ${ }^{\mathbb{Q}} \mathrm{T}-700$ and $70 \$$ for Hygochron ${ }^{\mathrm{TM}}$ i-button). They

Table 2 Description and distribution of sensors in the container. Characteristics of test carried out for this work (in italics)

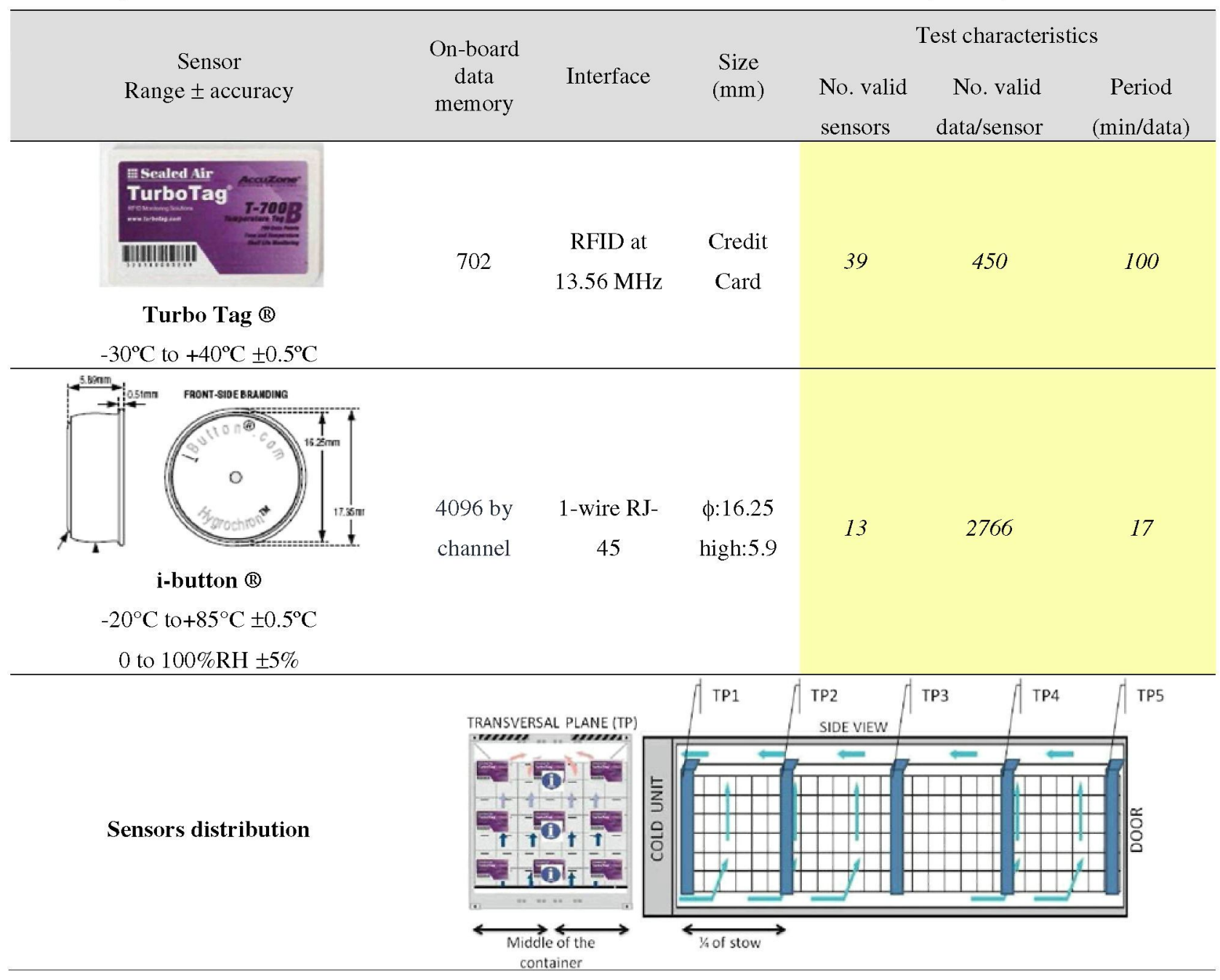


are autonomous in power supply during at least 1 year, furnished with on-board data memory and very easy-to-fix behavior regarding the load.

All communications with $\mathrm{T}-700$ series tags are carried out using an RFID reader DR-1 (RFID Interface 13.56 MHz). This is a small desktop USB device for use with a PC that runs with Session Manager Software. The Tag download requires $2 \mathrm{~s}$ on average with the RFID read distance around $5-10 \mathrm{~cm}$. For the ibutton sensor, the information transfer between the sensor and the $\mathrm{PC}$ is carried out by wire with momentary connection using a Blue Dot ${ }^{\mathrm{TM}}$ receptor; transmission is done at $125 \mathrm{kbps}$, using a 1-wire RJ45 to USB adaptor. The i-button allows gathering the information of the RH besides the temperature. The calibration of the sensor of $\mathrm{RH}$ included in the i-button is taken at $25^{\circ} \mathrm{C}$. Therefore, to obtain the most accurate humidity results, the manufacturer (Maxim 2009) proposes temperature compensation, and this was carried out in all the RH registered. Since the sensor of $\mathrm{RH}$ is capacitive, a shift of humidity reading is described when it is exposed to humidity level above $70 \%$; therefore, a software saturation drift compensation was implemented following the equation given by the manufacturer. Due to an internal memory available of 4096 data points by channel, it used a high temporal resolution (17 $\mathrm{min} /$ data in this experiment) versus a minor temporal resolution selected for TurboTag ( $100 \mathrm{~min} /$ data) that was limited by an internal available memory of 702 data (Table 2 ).

\section{Data Analysis}

In order to analyze the data from sensor recording, two different procedures were implemented: the psychrometric model and the reconstruction of the phase space.

The psychrometric charts were produced using the data collected from the i-button sensors, based on the ASABE model which computes complex parameters such as absolute humidity ( $\mathrm{kg}_{\text {vapour }} / \mathrm{kg}_{\text {dry }}$ air $)$ and enthalpy per unit mass ( $\mathrm{J} /$ $\mathrm{kg}_{\text {dry air }}$ ) from temperature and $\mathrm{RH}$ data. The psychrometric data ASAE Standard D271.2, defined in April 1979 and reviewed in 2005 (ASABE 2006) were used to calculate these psychrometric properties of the air.

On the other hand, following Eckmann and Ruelle (1985), the best way to reconstruct the phase space from a time series is using time delays. The technique is as follows. Let there be a time series $(t(k), y(k))$ with fixed time step. Then, we can construct the $N$-dimensional phase space $\left(Y_{1}, Y_{2}, \ldots, Y_{N}\right)$ from the time series by doing $Y_{i}=y\left(k+\Delta_{i}\right)$ with $i=1,2, \ldots, N$ and $\Delta_{1}=0$, where each $\Delta_{i}$ defines a time delay given by $t_{\mathrm{d} i}=t(k+$ $\left.\Delta_{i}\right)-t(k)$. Note that the time delay does not depend on step $k$, because the time step is fixed. That is, we represent the time series versus itself delayed in time. The value of the optimal time delays will be obtained by heuristics.

To compute the phase space on temperature series from RFID Tags and on enthalpy series calculated from i-button data, a filter was used to smooth the data. The smoothed points were computed by replacing each data point with the value of its fitted value. In our case, a window of 5 points was used. Two-dimensional phase spaces were performed plotting the temperature at time $t(k+\Delta)$ versus the temperature at time $t(k)$, where $\Delta$ corresponds to different steps. Different values of $\Delta$ were tested for RFID Tags (temperature) and i-buttons (enthalpy), respectively, looking for the optimal $\Delta$ in which the cyclic trajectories or attractor in the phase space showed the maximum area. The area of the different polygons that include the data points corresponding to cyclic behaviour in the phase space per sensor or sensor group was computed, using the MATLAB Function CONVHULLN, which returns the vertices and area, in ${ }^{\circ} \mathrm{C}^{2}$ (for temperature) and $\mathrm{J}^{2} \mathrm{~kg}^{-2}$ (for enthalpy), of refereed convex hull on phase spaces. This function allows users to manually select a set of points on the attractor in the phase space graph, and gives the smallest convex envelope that contains these points.

\section{Results and Discussion}

\section{Temporal Information}

In the monitored reefer, the set point temperature was $4{ }^{\circ} \mathrm{C}$. Taking into account all data of the 39 RFID Tags, the average temperature was $2.7^{\circ} \mathrm{C}$ above the set point, which is more than the $=0.5^{\circ} \mathrm{C}$ of variation recommended by the Standards for food distribution BS EN 12830:1999 (James et al. 2006; Jedermann et al. 2009).

The average of absolute minimum temperatures $(n=39$ sensors) was $5.4^{\circ} \mathrm{C}$, with the lowest registered temperature being $3.7^{\circ} \mathrm{C}$ corresponding to the sensor located near the evaporator outlet, while the maximum absolute temperature was registered at the evaporator inlet $\left(10.5^{\circ} \mathrm{C}\right)$ (Fig. 1).

Along the transoceanic transport, the average standard deviation ( $\mathrm{SD}, n=39$ sensors) was $\pm 0.17^{\circ} \mathrm{C}$, which is below the accuracy of $\pm 0.19^{\circ} \mathrm{C}$ estimated by Jederman et al. (2009) for RFID Tags; meanwhile, in the same period, the average spatial SD (calculated for sensors at different locations for the same instant, $n=215$ time data) almost quadrupled that value $\left( \pm 0.67{ }^{\circ} \mathrm{C}\right)$. Both values of SD increased a $51.98 \%$ and a $43.93 \%$, respectively, during the short sea shipping (SSS) in Spain (from Algeciras to Cartagena, 9.5 days).

In order to facilitate the handling of data from the 39 RFID Tags, a sensor clustering was carried out looking for similar patterns among time temperature series recorded by sensors at different locations in the container; ten groups were identified labeled from $\mathrm{A}$ to $\mathrm{J}$. In Table 3, the average values for the mean and the SD of temperatures for the complete journey are summarized, together with the time period required to reach temperature stability after the start-up and loading of the container, for each of those groups of sensors. For further 

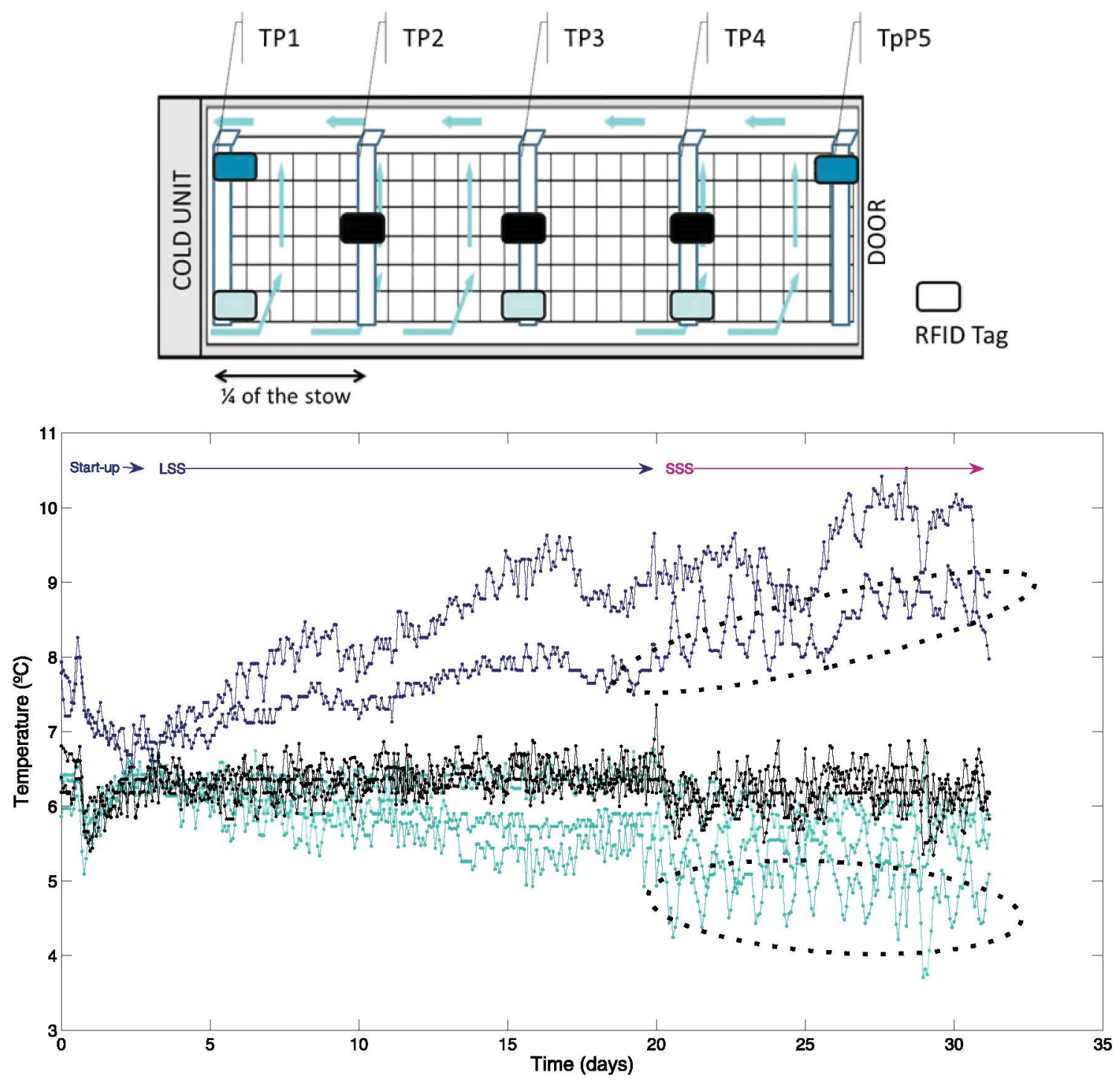

Fig. 1 Dynamics of temperature inside the container, registered by three groups of RFID Tags sensors, and corresponding location inside the container (upper part). Group B: in dark blue, group G: in light blue,

analysis, groups B (consisting of two RFID Tags, Table 3), G (three RFID Tags) and J (three RFID Tags) were selected, corresponding respectively to the hottest, the coldest and the most stable locations inside the reefer.

Figure 1 shows the temperatures along the transport corresponding to the selected sensors. During the SSS, daily cycles of temperature could be observed, which were especially noticeable in those sensors located at the outlet (light blue sensor) and at the return (dark blue sensor) of the refrigeration unit, respectively. Whenever the temperature increase registered at the inlet of the cold unit was above the established threshold, the cold unit was switched on causing an instantaneous decrease of temperature in the outlet.

According to the literature, when fresh products are exposed to a temperature below its tolerance threshold, chilling injury symptoms might appear (Hashim et al. 2012), for loads of group J: in black. The elliptic dotted curves indicate the daily cycles of temperature. LSS long sea shipping, SSS short sea shipping

lemons there is serious risk of alterations by its particular sensitivity to the combined effect of low temperatures and long periods of storage. The optimum storage temperature of lemons to avoid chilling injuries is $12-18{ }^{\circ} \mathrm{C}$, but these high temperatures combined with an RH of $85-90 \%$ favor the development of rotting (Artés-Hernández et al. 2010; Artes et al. 1993). Moreover, the temperature of $4{ }^{\circ} \mathrm{C}$ during 31 days of cold storage could induce chilling injuries. It looks like in this case, it was preferred to withstand a risk of chilling injuries when compared to the risk of rotting. Therefore the priority was to control rots and thus the low temperature selected for transport. The presence of rotting is a common commercial reason for rejection of lemons at the quality inspection during the unloading operation or at the consumer market. On the other hand, the visual impact created by rotting is much more striking than that of chilling injury, whose incidence is much more 
Table 3 Average of mean and SD of the temperature for ten sensor clusters along the complete journey and start-up time required to reach the temperature stability for each group of sensors. Color of rows corresponds to the color code used in Fig. 2

\begin{tabular}{ccccc} 
Sensor group & No. of sensors & Mean average $\left({ }^{\circ} \mathrm{C}\right)$ & SD average $\left( \pm{ }^{\circ} \mathrm{C}\right)$ & Start-up time (days) \\
A & 2 & 7.287 & 0.511 & 4.5 \\
B & 2 & 8.223 & 0.783 & 1.5 \\
C & 2 & 6.430 & 0.513 & 2.7 \\
D & 5 & 7.282 & 0.721 & 6.9 \\
E & 4 & 6.783 & 0.531 & 4.1 \\
F & 6 & 6.324 & 0.334 & 3.6 \\
G & 3 & 5.804 & 0.385 & 2.9 \\
H & 5 & 6.040 & 0.327 & 2.3 \\
I & 7 & 6.850 & 0.308 & 1.9 \\
\hline J & 3 & 6.278 & 0.244 & 1.9 \\
\hline
\end{tabular}

relevant during the marketing period and scarcely visible after cold storage.

Another critical point in this study is the occurrence of daily cycles during SSS, which could be due to the direct exposure of the reefer to sunlight in port and on the ship's deck. In August and in Southern Spain, noon outside temperature can easily exceed $35^{\circ} \mathrm{C}$; consequently, the large heat gain makes it far more difficult to control product temperatures (James et al. 2006). The built-in sensors of a standard refrigeration unit measure only the inlet and the outlet air temperature, but not the freight temperature (Lang et al. 2011). The on/off action would be improved if the temperature sensor measured the air surrounding the carton stack instead of the return air, according to James et al. (James et al. 2006) this would reduce overcooling of the product and temperature cycling.
Spatial Information

Figure 2 shows the phase diagram of temperature $\left(t_{\mathrm{d}}=\right.$ 1 (step) $100(\mathrm{~min} / \mathrm{step})=100 \mathrm{~min})$ for the three selected groups of sensors (B, G and J). Sensors belonging to the same group appear in the same color and in the same region of the phase diagram. The areas of the polygons that include all the data points of each sensor group quantify the variability of the temperature within each zone of the container. Consequently, group B (dark blue sensors) corresponds to the hottest zone of the container; with an average temperature that was $4.2^{\circ} \mathrm{C}$ above the set point $\left(4{ }^{\circ} \mathrm{C}\right)$ and due to its largest area on the phase space that equals $3.49\left({ }^{\circ} \mathrm{C}^{2}, \Delta=1\right)$, can be identified as the zone subjected to the highest temperature gradients. In the upper part of the reefer, we found the most stressed fiuits and the highest risk to rotting
Fig. 2 Phase diagram for temperature with $\Delta=1\left(t_{\mathrm{d}}=\right.$ 1 (step) $\cdot 100(\min /$ step $)=100 \mathrm{~min})$ for RFID Tag sensors: group B (dark blue), group G (light blue) and group J (black). Double arrow indicates the overall variation of temperature inside the reefer (from $3.71^{\circ} \mathrm{C}$ to $10.53^{\circ} \mathrm{C}$ )

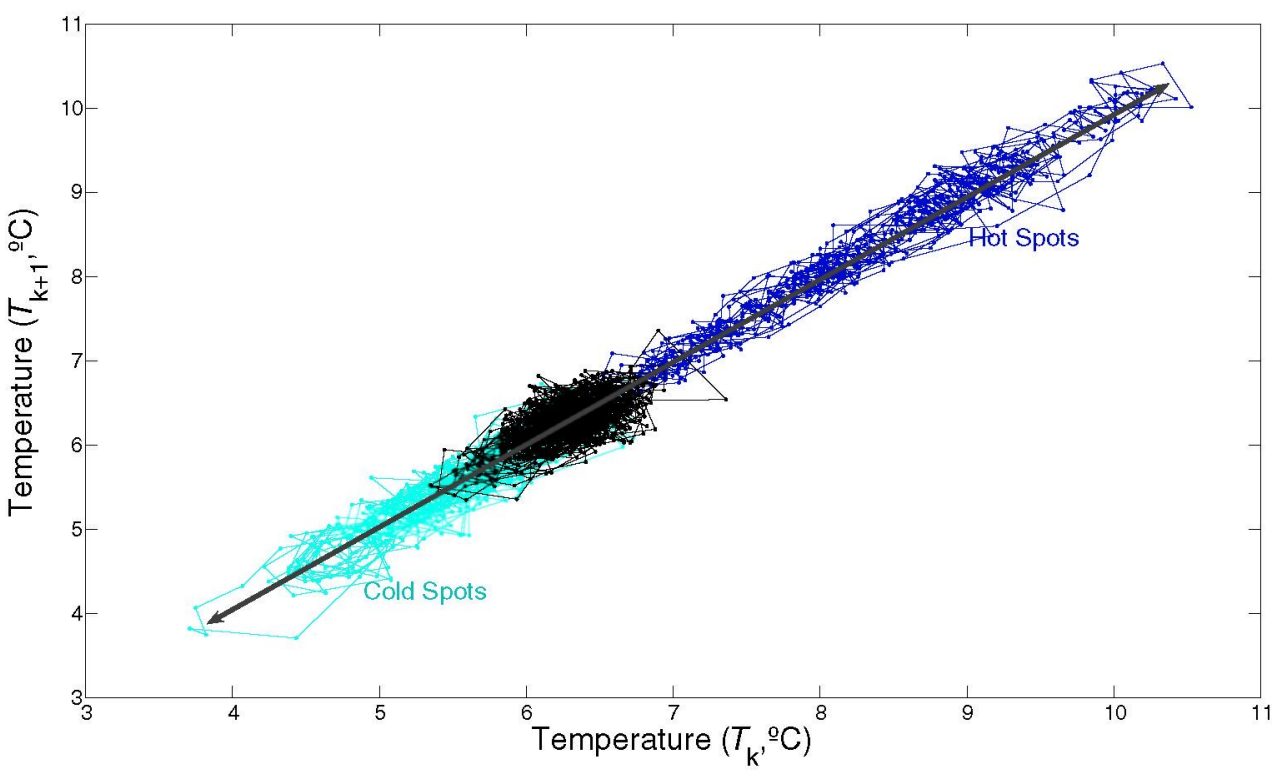


development. Group G (light blue sensors) is located on the base of the phase diagram with a similar area of $3.48\left({ }^{\circ} \mathrm{C}^{2}, \Delta=1\right)$ and showing an average temperature of $5.8^{\circ} \mathrm{C}$. Therefore, it provides the coldest points inside the container, with the highest risk of chilling injury, also with a large temperature gradient. Group J (black sensors) identifies points at the center (average temperature $6.3^{\circ} \mathrm{C}$ ) where the temperature is more stable. This behaviour is also confirmed by the lowest area that is covered by sensor group J within the phase diagram $1.95\left({ }^{\circ} \mathrm{C}^{2}, \Delta=1\right)$.

The total range of variation of the cargo temperature for the complete journey was $6.8^{\circ} \mathrm{C}$, which is in accordance with previous published data that report deviations above $5{ }^{\circ} \mathrm{C}$ during long transports (Jedermann et al. 2009; Lang et al. 2011). The phase diagram of temperatures emphasizes the difference between the temperatures recorded by the sensors at different locations inside the container. Depending on the location of the cargo the products may be under large differences in cooling (Jedermann et al. 2009). The areas computed on these diagrams provide an idea of the thermal stress (Villarroel et al. 2011) (temporal gradients of temperature) to which the fruits were subjected during the long transport.
Complex Information

During the long sea shipping (LSS), or transoceanic transport, the average SD of temperature along time was $\pm 0.19^{\circ} \mathrm{C}$ for all $\mathrm{i}$ button ( $n=13$ sensors), a value above the accuracy of $\pm 0.09{ }^{\circ} \mathrm{C}$ computed by Jederman et al. (2009) for i-buttons, while the average spatial SD was $=0.47{ }^{\circ} \mathrm{C}$ ( $n=1,540$ time data). It is observed that in this experiment, both average SDs double these values during the SSS. The i-buttons located at the most relevant locations inside the container were considered for further analysis: evaporator inlet and outlet, central reefer position and door end.

Figure 3 shows the temporal evolution of temperature from selected i-button sensors for the complete journey. The higher time resolution of i-button sensors allows users to confirm the occurrence of daily temperature cycles, once the load reaches the Spanish port of Algeciras and is further transferred to the second vessel, an oscillation that is verified in all locations in the container.

The average $\mathrm{RH}$ recorded for the $13 \mathrm{i}$-buttons was $90.7 \%$ (the recommended RH for lemons cold storage is $85-90 \%$;
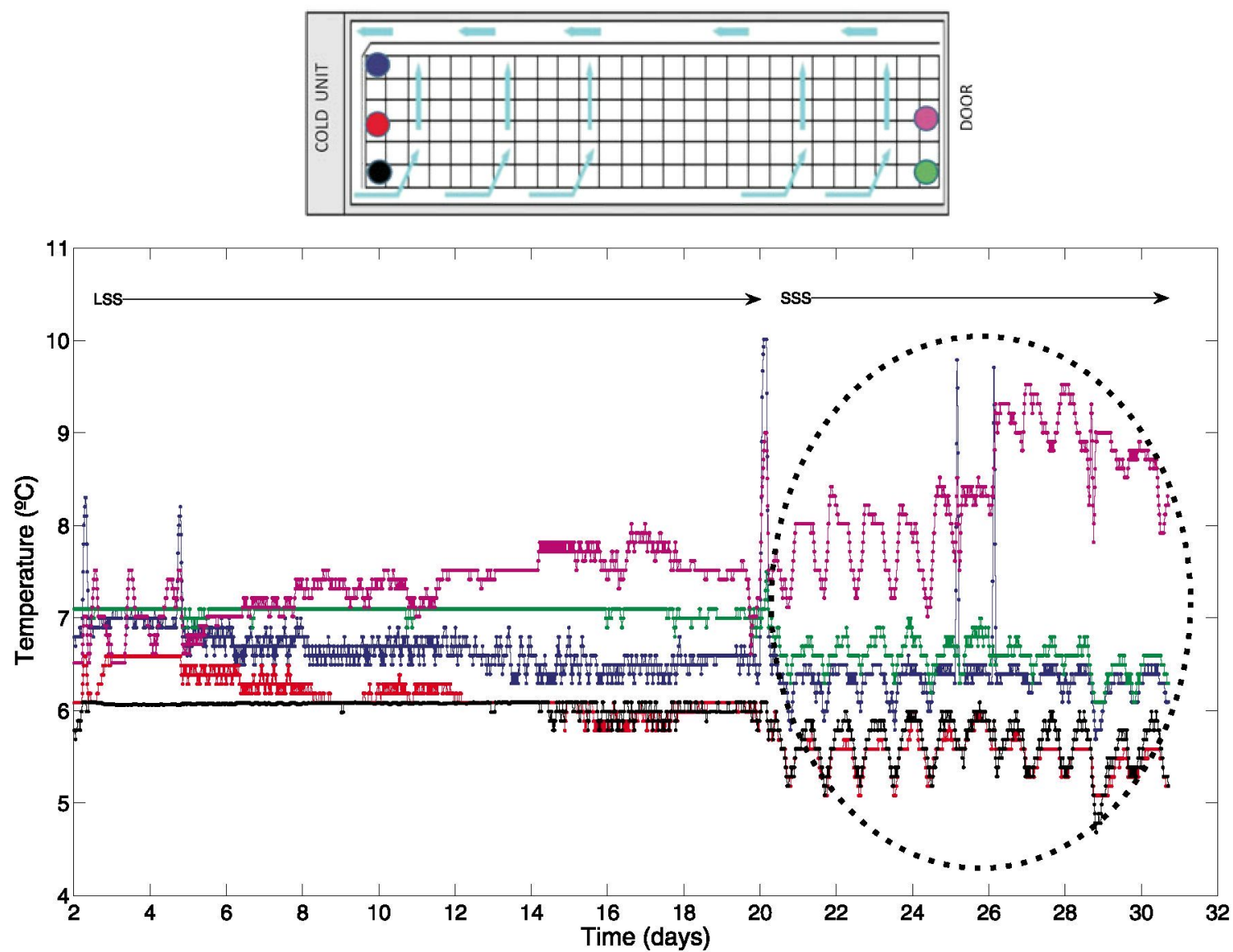

Fig. 3 Time series of temperature corresponding to five i-buttons and its location inside the container (upper part). LSS long sea shipping transport from Montevideo to Algeciras, SSS short sea shipping from Algeciras to Cartagena. Sensor located at evaporator inlet and outlet in blue and black, respectively, at central position in red and sensors near to the door in purple and green. The dotted elliptic curve indicates the daily cycles of temperature during the SSS 
Thompson 2007). However the psychometric chart (Fig. 4) shows a large heterogeneity in the thermohygrometric conditions of the reefer environment. The $\mathrm{RH}$ variability increases from a spatial average SD of $\pm 2.4 \%$ during the LSS to a level of $\pm 4.1 \%$ during the SSS. The highest RH range (considering sensors at different locations for the same instant) was $26.5 \%$, which was reached at day 28.8 during the SSS. These extreme values of $\mathrm{RH}$ were recorded by the sensors located longitudinally in the outermost reefer positions (see green dots overlying the red and purple markers in Fig. 4). In addition, it is possible to detect condensations, as indicated by red sensor in Fig. 4, since its RH was over $99 \%$ during several periods, that is to say it lead to saturation conditions.

Figure 4 also shows the position in our container of the five selected sensors: blue (located at the cooling unit inlet), black (at the cooling unit output), red (near to the cooling unit but at an
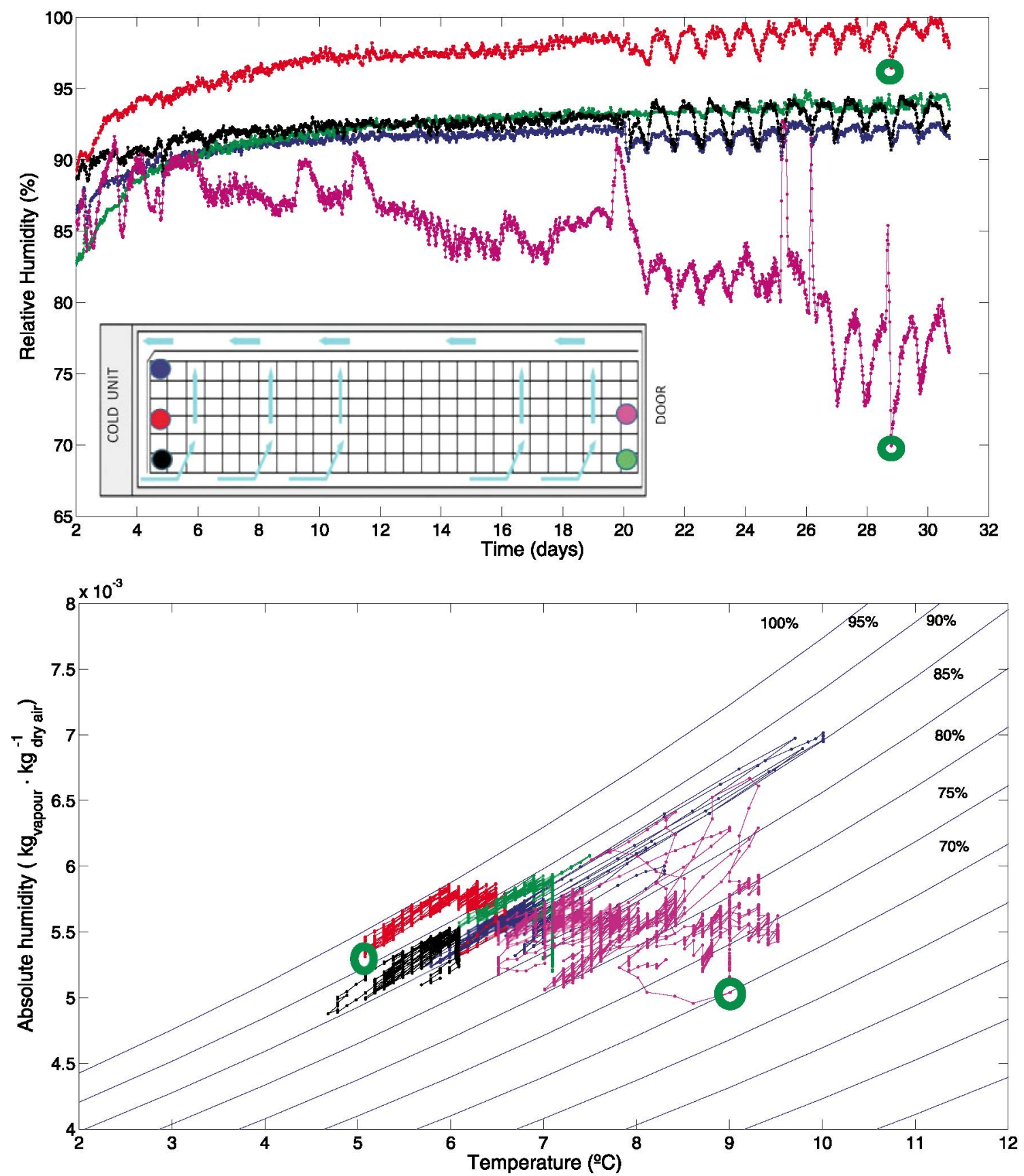

Fig. 4 Time series of relative humidity (up) and psychrometric chart (down) corresponding to five i-buttons. Sensors located at evaporator inlet and outlet in blue and black, respectively, at central position in red and sensors near the door in purple and green. The $\mathrm{RH}$ in the psychometric chart (down) is represented by the blue curved lines which are equi-spaced by $5 \%$. Green dots note the highest $\mathrm{RH}$ range of variation $(26.5 \%)$ reached at day 28.8 
average height) and purple and green (near to the door). Observing the evolution of temperature (Fig. 3) and RH (Fig. 4), there is no similar pattern of red and blue sensors (transversal plane 1, Table 2) and purple and green sensors (transversal plane 5, Table 2) in the first phase of transport, as it is observed in the enthalpy chart (Fig. 5), wherein up to 20 days sensors behaved almost identically. The purple and red sensors positioned in the middle of the load (front and back) seem to correspond to areas where the air velocity is not very high, so it seems that they are more or less out of the main airflow stream. The different height positions of the sensors in each transversal plane involved different expositions to the air flow and different behavior in terms of temperature and $\mathrm{RH}$, but its enthalpy behaves similarly to the 20 days, as it would under steady state. At such point (20 days), a peak temperature occurs which affects the outermost sensors (purple and blue), elevating abruptly the temperature by about $3{ }^{\circ} \mathrm{C}$, so that both exceed the threshold of $9{ }^{\circ} \mathrm{C}$ in which the respiration heat from lemons becomes considerable and could exceed $610 \mathrm{kcal} /$ tons day (Artés-Hernández et al. 2010; Artes et al. 1993). This increase did not affect the air surrounding the red and black sensors. The temperature increase in the return is immediately corrected thanks to the high air flow, while at the position of the purple sensor at the end of the container, the reduced air flow is not able to absorb all the heat generated in the peak. The increase in fruit respiration in that position also causes an increase of the differential temperature between the coldest and warmest locations at the reefer on successive days. This change was clearly addressable by tracking enthalpy in transversal plane 5 showing the separation of the green and purple sensors thereafter.

In relation to the computed enthalpy of the air inside the reefer, Fig. 6 shows the phase diagrams for the i-button located at the inlet of the cold unit. It can be observed that any of the $\Delta$ analyzed reproduce the cyclic behavior of the enthalpy in the phase space, although the more appropriate reconstruction of the attractor is achieved with a time step $\Delta=$ 5 equivalent to a time delay $t_{\mathrm{d}}=5(\mathrm{step}) \cdot 17(\mathrm{~min} / \mathrm{step})=85 \mathrm{~min}$ (Xingyuan and Chao 2006).

Table 4 presents the values of the areas of attractors computed on phase diagrams of enthalpy $(\Delta=5)$ for all i-buttons (from 1 to 13) along LSS and SSS transportation. Regarding spatial variations inside the container, the coefficients of variation for both periods were above $100 \%$, indicating a large variability of storage conditions for varying locations inside the reefer, as shown by RFID Tags. The SSS showed the highest areas, that once more indicate sudden changes in the inner atmosphere during this period. The main changes of enthalpy are coincident by the opening of the doors for official inspections occurred during the SSS. Sensor 10 located near the door, reached an unusual high value of area $\left(1,069 \mathrm{~J}^{2} \mathrm{~kg}^{-2}\right)$, which could be due to the extraction of inspection samples in port during SSS. This sensor showed a temperature rise during this period of $22^{\circ} \mathrm{C}$. Even excluding sensor 10 , the average value of the areas during SSS was five times higher than that corresponding to LSS. Considering LSS and SSS periods, sensor 1, located at the inlet of the cold unit,

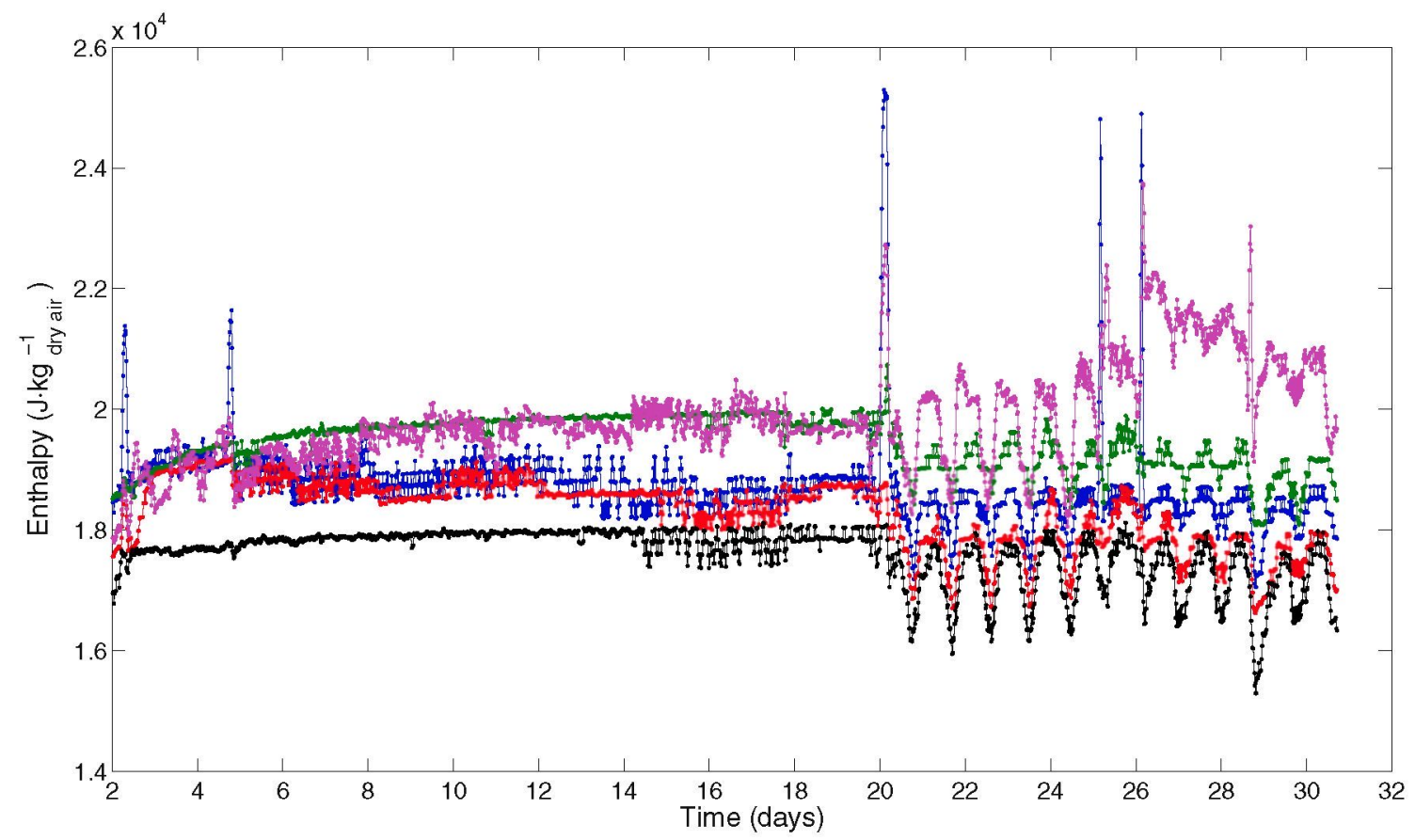

Fig. 5 Time series of enthalpy corresponding to five i-buttons. Sensor located at evaporator inlet and outlet, in blue and black, respectively, at central position in red and sensors near the door in purple and green 
Author's personal copy

Food Bioprocess Technol
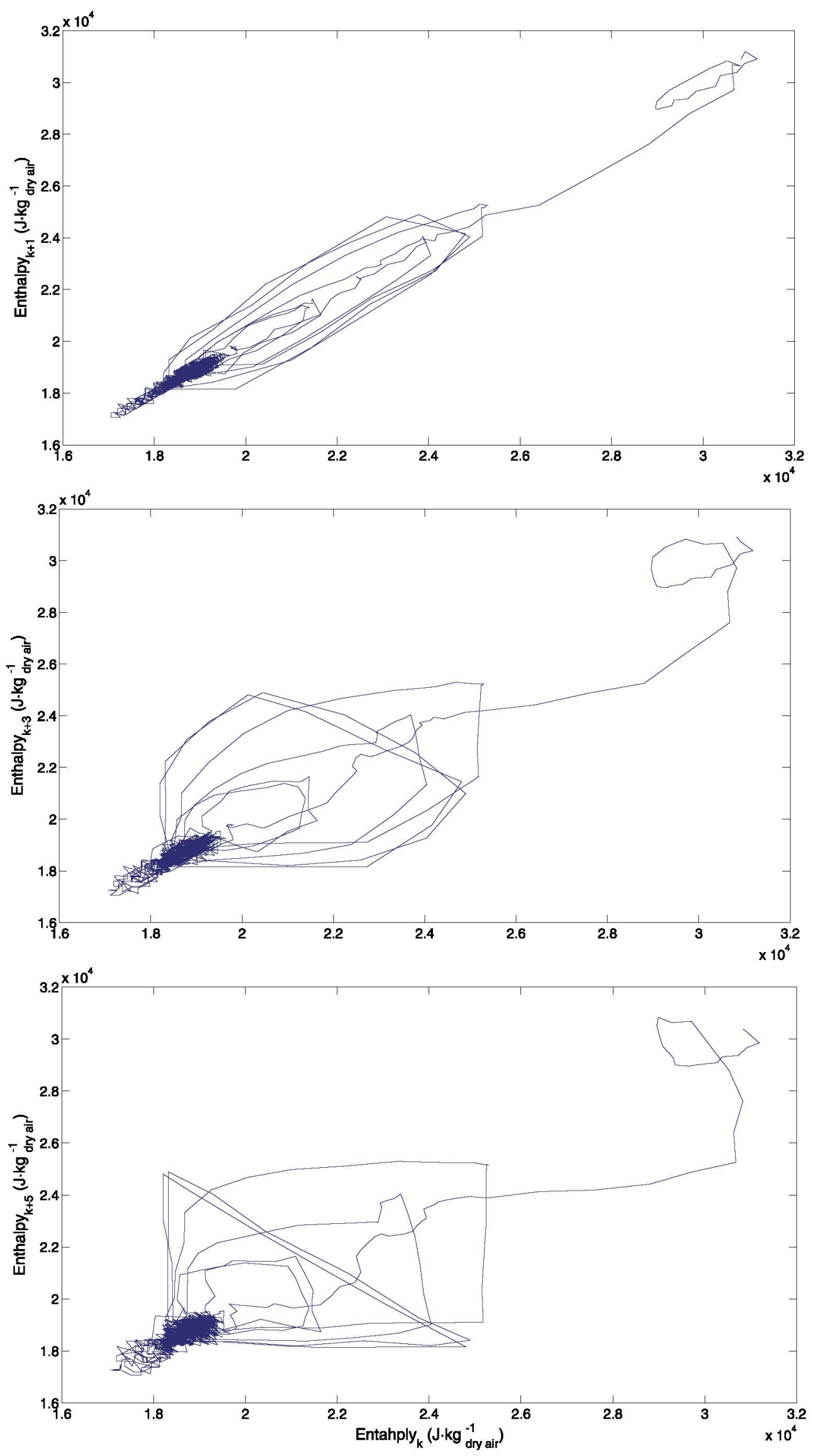

Springer 
Fig. 6 Enthalpy phase diagrams for $\Delta=1$ and $t_{\mathrm{d}}=1$ (step) $\cdot 17(\mathrm{~min} / \mathrm{step})$ $=17 \mathrm{~min}, \Delta=3$ and $t_{\mathrm{d}}=3(\mathrm{step}) \cdot 17(\mathrm{~min} / \mathrm{step})=51 \mathrm{~min}$ and $\Delta=5$ and $t_{\mathrm{d}}=$ 5 (step) $\cdot 17(\mathrm{~min} / \mathrm{step})=85 \mathrm{~min}$, for the i-button (sensor 1) located at the inlet of the evaporator

is the sensor that presented the highest values of area, which indicates that this position is a good location to detect the abnormalities occurred in such container. In this place, an increase in enthalpy of $27 \%$ was reached during the door opening, with respect to stability conditions.

In Fig. 7, the enthalpy series during start-up time, LSS and SSS, is reconstructed in a two-dimensional phase space with $\Delta$ $=5$ of sensor 1 . Figure 7 illustrates three different patterns of attractors that allow identifying different behavior through the transport. It is shown that these three attractors present identifiable shapes for the different periods during transport. In other research areas pattern recognition was used to identify different behaviors in time series. Huang et al. (2009) applied the phase space of gastrointestinal pressure to study the real motility of human stomachs; different shape of attractors were found and identified with two different phases of stomach contractions.

During the SSS period the highest variations of temperature, $\mathrm{RH}$ and enthalpy data were observed. This would indicate that thermal stress experienced by fruits during these last 9.5 days of transport was much higher than that during the rest of the journey, becoming a critical point in the logistics process. It has to be stated that within such a 9.5 day period, only 1.3 days correspond to actual sailing, indicating that $86 \%$ of the time the cargo was waiting at the port, so that phase of transport had the greatest impact on the quality of the load and that it is susceptible of improvement by simply decreasing timeouts. It is interesting to remark that $39.7 \%$ of the whole trip duration corresponds to delay times during loading/unloading operations and inspections.

The enthalpy rise, specially the one detected during the SSS period, could lead to an increase in energy consumption of the cold unit that can also be quantified in terms of areas. Enthalpy is a measure of the total energy of a thermodynamic system and it is considered here as the heat content of the air surrounding the fruits. The enthalpy is the preferred expression of system energy changes, because a change in enthalpy takes account of energy transferred between the environment and the system under study. Thus, the increase in air enthalpy registered along SSS represents mainly the heat gain from the outer environment and from the fruit respiration. The use of the enthalpy for monitoring a refrigeration transport allows a better comparison between behaviors in the different zones of the container. Therefore, the enthalpy is an appropriate variable to be used as input in a control strategy, from several points of view: (1) detection of failures, (2) isolation of abnormalities in cold storage, and (3) reduction of energy consumption.

Similar proposals have been formulated in other fields. Aktacir et al. (2008) presented an enthalpy-based control system for air conditioning in buildings, that incorporated a free cooling equipments, which implies the use of outside air looking for the maximum energy saving. They proposed a control system based on enthalpy instead of temperature, since enthalpy considers the additional power required to dehumidify the outdoor air. Villarroel et al. (2011), in animal welfare studies, proposed the use of phase space of enthalpy as indicator of physiological and behavioral stress in pigs during long distance transports.

\section{Conclusions}

This work shows phase and time sequencing diagrams as a novel methodology and reveals a significant heterogeneity of temperature and relative humidity at different locations in a container during a transoceanic transportation. The maximum range of variation registered by RFID Tags was $6.8^{\circ} \mathrm{C}$, being the maximum spatial range (same time, different location) $6.6{ }^{\circ} \mathrm{C}$, which occurred at SSS periods. These facts highlight the ineffectiveness of the present temperature control system of a standard refrigeration unit. The current availability of low cost sensors facilitates the multidistributed supervision of temperature and relative humidity inside a container and promotes overcoming this limitation.

In this work, a methodology for the analysis of data series is proposed, based on the representation of the phase diagram. To the authors' knowledge, phase diagrams have never been attempted thus far to study the temperature and the enthalpy in cold chambers and containers. Phase graphs allow users to highlight, in a confined space, the enormous differences in storage conditions within the container in which the fruits travel.
Table 4 Areas calculated from the phase space of enthalpy for 13 ibuttons, along the LSS and the SSS periods, and their corresponding means (M), standard deviations (SD) and coefficient of variations (CV).
For SSS an outlier value was found for sensor 10 and it was avoided in calculus of $\mathrm{M}, \mathrm{SD}$ and $\mathrm{CV}$. Color of columns correspond to same color code for sensors identification used in Figs. 3, 4 and 5

\begin{tabular}{|c|c|c|c|c|c|c|c|c|c|c|c|c|c|c|c|c|}
\hline \multicolumn{10}{|c|}{ i-Button area $\mathbf{~} \mathbf{1 0}^{\mathbf{6}}\left(\mathbf{J}^{\mathbf{2}} \mathbf{k g}^{-\mathbf{2}}, \Delta=\mathbf{5}\right)$} \\
\hline & $\mathbf{1}$ & $\mathbf{2}$ & $\mathbf{3}$ & $\mathbf{4}$ & $\mathbf{5}$ & $\mathbf{6}$ & $\mathbf{7}$ & $\mathbf{8}$ & $\mathbf{9}$ & $\mathbf{1 0}$ & $\mathbf{1 1}$ & $\mathbf{1 2}$ & $\mathbf{1 3}$ & $\mathbf{M}$ & SD & CV\% \\
\hline LSS & 8.76 & 1.10 & 1.19 & 0.18 & 0.45 & 0.69 & 0.47 & 2.74 & 1.31 & 3.16 & 0.56 & 1.36 & 1.50 & 1.81 & 2.27 & 125.52 \\
\hline SSS & 56.53 & 2.60 & 4.36 & 0.89 & 1.58 & 3.03 & 3.89 & 19.83 & 3.05 & $* 1069.0$ & 4.26 & 8.44 & 1.84 & 9.19 & 15.76 & 171.45 \\
\hline
\end{tabular}

\footnotetext{
${ }^{a}$ Not considered for $\mathrm{M}, \mathrm{SD}$ and $\mathrm{CV}$
} 
Fig. 7 Enthalpy phase diagrams with $\Delta=5$ for the i-button (sensor

1) located at the inlet of the evaporator corresponding to a start-up time; $\mathbf{b}$ long transoceanic transport from Montevideo to Algeciras $(L S S)$; $\mathbf{c}$ short transport from Algeciras to Cartagena $(S S S)$; and $\mathbf{d}$ complete journey. The red line in panels $\mathbf{a}, \mathbf{b}$ and $\mathbf{c}$ indicates the area selected and computed in $\mathrm{J}^{2} \mathrm{~kg}^{-2}$, using Matlab function CONVHULL
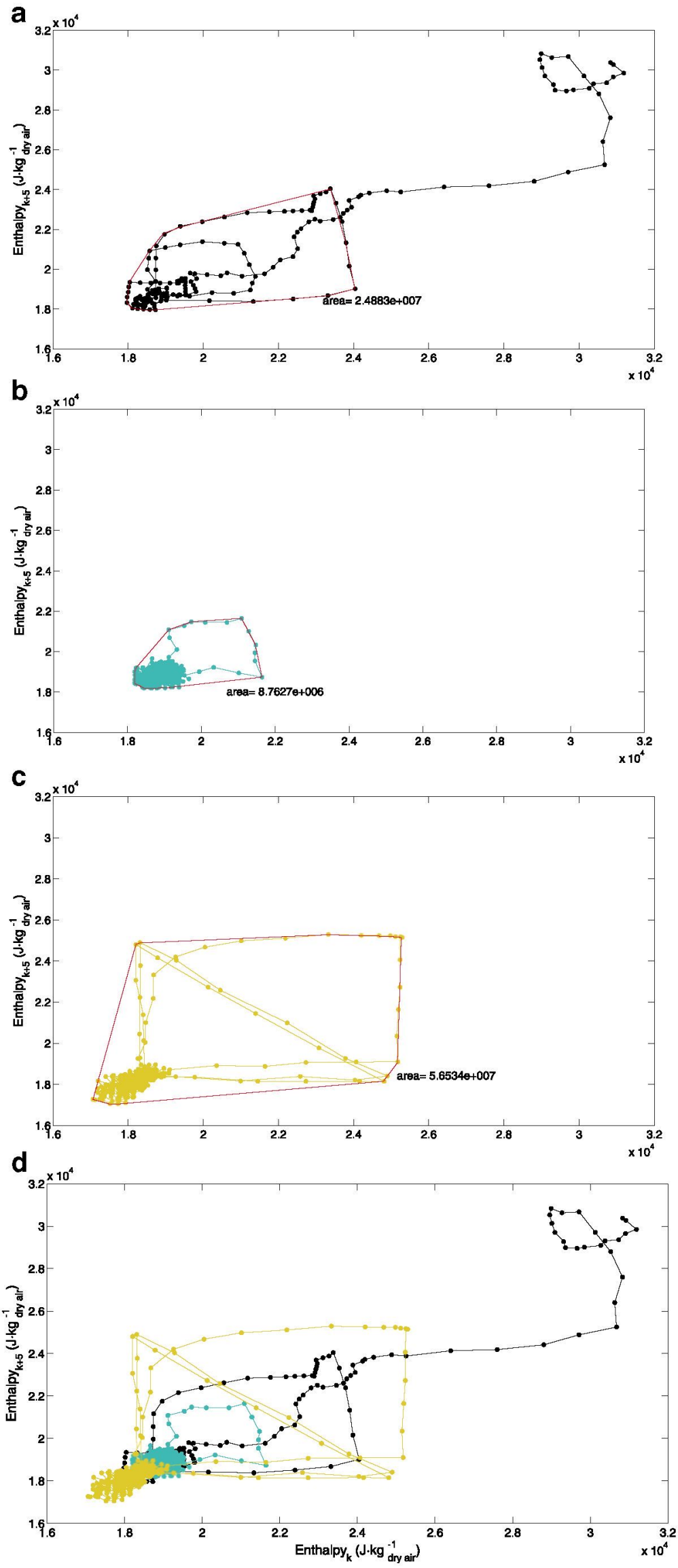
Areas of the attractors identified within the enthalpy phase diagrams, computed for the SSS period, were five times higher than those computed for LSS, with coefficients of variation above $100 \%$ in both cases. This heterogeneity will show up primarily during the subsequent shelf life evolution of the fruits in the marketing period. In addition, phase diagrams based on enthalpy data represent the changes in the heat content of the air, and thus facilitate the detection of events, such as door opening, because the enthalpy calculated from the values of temperature and relative humidity, simultaneously displays the combined effect of both variables on storage conditions. It is remarkable that phase diagrams allow compressing the information due to its cyclic shape, thus being independent of the timescale, thus allowing the comparison of trials with very different duration.

This work proposes the use of enthalpy and phase diagrams as a part of a decision support tool for monitoring refrigerated goods during cold storage and transportation. It is important to note that this procedure (phase space of enthalpy) has potential applicability on any agro food processes in which temperature and relative humidity are the control variables of the process, for example, in food dryers or in food maturation rooms (cheese, ham). Further work is being carried out with other long-distance transport and different fruits to validate these results.

Acknowledgments We thank the enterprises MILAGRO (Uruguay) and VICTOR GARRIGÓS S.A. (Spain) and their staff for technical help in loading, unloading operations and placement of sensors, as well as IBERIA pilots for their assistance in sensors transportations. This study was funded by the Spanish Government through SMART-QC project (GL2008-05267-C03-03) and FRUTURA (109RT0383) International Net of CYTED. We also thank them for their support to the Technical University of Madrid and the International Campus of Excellence CEI Moncloa/UPM-UCM.

\section{References}

Aktacir, M. A. (2012). Performance evaluation of different air-side economizer control methods for energy efficient building. ISI BILIMI VE TEKNIGI DERGISI-Joumal of Thermal Science and Technology, $32,19-30$.

Aktacir, M. A., Buyukalaca, O., Bulut, H., \& Yilmaz, T. (2008). Influence of different outdoor design conditions on design cooling load and design capacities of air conditioning equipments. Energy Conversion and Management, 49, 1766-1773. doi:10.1016/j.enconman.2007.10.021.

Artés-Hernández F., Gómez Di Marco P., Aguayo E., Escalona V., Tomás A., Artés-Calero F. (2010) Empleo de atmósferas controladas en el tratamiento cuarentenario durante el transporte frigorífico marítimo del limón a Japón y a EEUU [Use of controlled atmospheres in quarantine treatment during maritime refrigerated transport of lemon to Japan and U.S]. In: UPM-FRUTURA (Ed.), Retos y soluciones tecnológicas en logística y transporte refrigerado de frutas y hortalizas, Madrid. pp. 32-44

Artes, F., Escriche, A. J., \& Marin, J. G. (1993). Treating primofiori lemons in cold-storage with intermittent warming and carbondioxide. Hortscience, 28, 819-821.
ASABE. (2006) ASAE D271.2 APR1979 (R2005). Psychrometric Data., ASABE Standards. pp. 20-27

Barreiro P., Correa E.C., Arranz F.J., Diezma B., Ruiz-García L., Villarroel M., Robla J.I., García-Hierro F.J. (2010) Smart sensing applications in agriculture and food. In: Smart sensors: technology, developments and applications. Nova Science Publishers, New York.

Bruin, S., \& Jongen, T. (2010). Food process engineering: the last 25 years and challenges ahead. (vol 2, pg 42, 2003). Comprehensive Reviews in Food Science and Food Safety, 9, 601-601. doi:10.1111/ j.1541-4337.2010.00139.x.

Bulut, H., \& Aktacir, M. A. (2011). Determination of free cooling potential: a case study for Istanbul, Turkey. Applied Energy, 88, 680-689. doi:10.1016/j.apenergy.2010.08.030.

Costa, C., Antonucci, F., Pallottino, F., Aguzzi, J., Sarria, D., \& Menesatti, P. (2013). A review on agri-food supply chain traceability by means of RFID technology. Food and Bioprocess Technology, 6 , 353-366. doi:10.1007/s11947-012-0958-7.

Eckmann, J. P., \& Ruelle, D. (1985). Ergodic theory of chaos and strange attractors. Review of Modern Physics, 57, 617-656.

García Hierro J., Barreiro Elorza P., Ruiz García L., Robla Villalba J.I. (2010) Development of smart sensing devices for ubiquitous supervision of the cold chain: application to perishable commodities. International Conference on Agricultural Engineerig. AgEng 2010. Towards Environmental Technologies, Clermont-Ferrand, France

Garcia, M. R., Vilas, C., Banga, J. R., \& Alonso, A. A. (2007). Optimal field reconstruction of distributed process systems from partial measurements. Industrial \& Engineering Chemistry Research, 46, 530 539. doi:10.1021/ie0604167.

Hashim, N., Bin, J. R., Baranyai, L., Rahman, R. A., Osman, A., \& Zude, M. (2012). Kinetic model for colour changes in bananas during the appearance of chilling injury symptoms. Food and Bioprocess Technology, 5, 2952-2963. doi:10.1007/s11947-011-0646-Z.

Huang, B., Yan, G., Zan, P., \& Li, Q. (2009). Study on gastric interdigestive pressure activity based on phase space reconstruction and FastICA algorithm. Medical Engineering \& Physics, 31, 320327. doi:10.1016/j.medengphy.2008.04.017.

James, S. J., James, C., \& Evans, J. A. (2006). Modelling of food transportation systems - a review. International Journal of Refrigeration, 29, 947-957. doi:10.1016/j.jirefrig.2006.03.017.

Jedermann, R., Geyer, M., Praeger, U., \& Lang, W. (2013). Sea transport of bananas in containers - parameter identification for a temperature model. Journal of Food Engineering, 115, 330-338. doi:10.1016/j. jfoodeng.2012.10.039

Jedermann, R., Ruiz-Garcia, L., \& Lang, W. (2009). Spatial temperature profiling by semi-passive RFID loggers for perishable food transportation. Computers and Electronics in Agriculture, 65, 145-154. doi:10.1016/j.compag.2008.08.006.

Juriaanse, A. C. (1999). Changing pace in food science and technology: examples from dairy science show how descriptive knowledge can be transferred into predictive knowledge. Trends in Food Science \& Technology, 10, 303-306. doi:10.1016/s0924-2244(00)00009-1.

Laguerre, O., Hoang, H. M., \& Flick, D. (2013). Experimental investigation and modelling in the food cold chain: thermal and quality evolution. Trends in Food Science \& Technology, 29, 87-97. doi: 10.1016/j.tifs.2012.08.001.

Lang, W., Jedermann, R., Mrugala, D., Jabbari, A., Krieg-Brueckner, B., \& Schill, K. (2011). The "Intelligent Container"- a cognitive sensor network for transport management. IEEE Sensors Journal, 11, 688 698. doi: $10.1109 /$ jsen.2010.2060480.

Maxim. (2009) Hygrochron temperature/humidity logger iButton with $8 \mathrm{~kb}$ data-log memory. Datasheet, Sunnyvale, CA. pp. 53

Packard, N. H., Crutchfield, J. P., Farmer, J. D., \& Shaw, R. S. (1980). Geometry from a time-series. Physical Review Letters, 45, 712-716. doi:10.1103/PhysRevLett.45.712.

Pathare, P. B., Opara, U. L., Vigneault, C., Delele, M. A., \& Al-Said, F. A.J. (2012). Design of packaging vents for cooling fresh horticultural 
produce. Food and Bioprocess Technology, 5, 2031-2045. doi:10. 1007/s11947-012-0883-9

Rodriguez-Bermejo, J., Barreiro, P., Robla, J. I., \& Ruiz-Garcia, L. (2007). Thermal study of a transport container. Journal of Food Engineering, 80, 517-527. doi:10.1016/j.jfoodeng.2006.06.010.

Takens, F. (1981). Detecting strange attractors in turbulence, dynamical systems and turbulence (pp. 366-381). Berlin: Springer.

Thompson, J. E. (2007). Sistemas de almacenamiento. In A. A. Kader (Ed.), Tecnología postcosecha de cultivos hortofrutícolas (pp. 131147). Davis, California: University of California.
Villarroel, M., Barreiro, P., Kettlewell, P., Farish, M., \& Mitchell, M. (2011) Time derivatives in air temperature and enthalpy as non-invasive welfare indicators during long distance animal transport. Biosystems Engineering, 110, 253-260. doi:10.1016/j.biosystemseng.2011.07.011.

Xingyuan, W., \& Chao, L. (2006). Researches on chaos phenomenon of EEG dynamics model. Applied Mathematics and Computation, 183, 30-41. doi:10.1016/j.amc.2006.04.025.

Yahla M.E. (2009) ¿Es necesario producir más frutas y verduras en el mundo? [Is it necessary to produce more fruits and vegetables in the world?] Horticultura Internacional 69:3. 